\title{
Perfil del sujeto eclesial evangelizador de la gran ciudad. El caso latinoamericano (II)
}

\author{
Pedro Trigo, \\ Centro Gumilla, \\ Caracas, Venezuela.
}

\section{La comunidad cristiana}

El segundo modelo de sujeto evangelizador de la gran ciudad es el de la comunidad cristiona. Si el primero, la institución eclesiástica, lo hemos estudiado en la primera parte de este articulo, por su capacidad instalada y por su correspondencia con las macroinstituciones, que pretenden moldear a la gran ciudad, el modelo de la comunidad nos sale al paso por todo lo contrario, es decir, por su condición ulópica y altemativa, que tiene fuerte apoyo en las fuentes escriturísticas y en la literalura de los tres primeros siglos, lo que para los cristianos tiene un valor, si no siempre paradigmático, sí fuertemente inspirador e incluso provocador.

\section{Comunidad y pueblo de Dios}

\section{1. ¿Dos modelos excluyentes?}

Mientras la institución eclesiástica es un sujeto fáctico, es decir, que funciona de hecho, aunque no se prescriba en ningún documento, con la comunidad pasa lo contrario: es propuesta con gran énfasis, pero apenas es puesta en práctica, si excluimos las versiones fundamentalistas, que sí tienen un cierto desartollo. Para comprender esta paradoja es importante captar que los dos modelos son inversamente proporcionales, y que, históricamente, se puede comprobar que el primero desplazó al segundo, aunque sin negarlo nunca, en teoría. El desplazamiento consistió en hacer del modelo comunitario un ideal siempre exaltado, pero, por su exigencia intrínseca, no exigible a todos, aunque se haya recomendado de forma encarecida a quien se quiera señalar, en la vida cristiana. El resultado ha sido el establecimiento de dos iglesias: la primera, de masas, basada en exigen- 
cias mínimas para que en ella cupieran, en la práctica, todos, y la segunda, de minorias.

En la primera, es evidente que el sujeto evangelizador tiene que ser la institución eclesiástica, mientras la masa se convierte en mero destinatario de su acción. En la segunda, todos formarían un sujeto eclesial evangelizador. La misión de la Iglesia de minorias sería fecundar, como levadura, la Iglesia de masas, pero no sólo con su ejemplo y acción direcla, sino reproduciéndose en su seno como células diluidas, más que como núclcos de intensidad, que irradiarían energía cualitaliva sobre la masa, contrarrestando, así, su inercia. Eso ocurrió, al menos en alguna medida. Pero también ocurtió que el modelo institución eclesiástica-masa, al constituirse en el modelo fundamental, tendió a sacralizarse como paradigma, y se introdujo de forma subrepticia también en la Iglesia de minorías. De esa manera, el esquema jerárquico comenzó a minar, desde dentro, la fraternidad evangélica. Es irónico, que la Iglesia-comunidad acabó siendo llamada "vida regular".

\subsection{Jesús: movimiento de reunión y de reciprocidad de dones}

Para aclararnos en este asunto, tenemos que recordar to que ya dijimos en la primera parte de este artículo: el primer referente de Jesús no es, por supuesto, la Iglesia (que estaba fuera de su horizonte), ni su grupo de discípulos, sino el pueblo de Dios, dentro del cual privilegió a aquellos que estaban en la base de la pirámide social: los pobres (para él, los necesitados, abatidos y despreciados), y del que no estaban excluidos los tenidos como pecadores públicos.

Jesús es enviado como "gloria de su pueblo" y como "luz de las naciones" paganas, como "alianza con el pueblo de Dios", en favor de toda la humanidad. Por eso, la obra de Jesús puede ser caracterizada como un movimiento de reunión, de unificación. Esta convocatoria no gira alrededor de él, como si él fuese el centro que, con su presencia iluminadora y sanadora, se convierte en una especie de lugar sagrado, un santuario. Jesús no sigue el modelo del lercer Isaías (caps. 60 y 62): una ciudad hacia la que confluyen todos los pueblos, porque es el centro del mundo, el punto donde se unen el cielo y la lierra. Tal como lo presenta Marcos $(1,35-39)$, eso es lo que pretendían sus discípulos y la gente, cuando Jesús se retira, tras sus primeros éxitos y portentos. Aquéllos lo instan a que regrese a Cafamaún y desde ahí, atienda a todos, mientras toda la gente acudía a él. Pero Jesús desestima esta propuesta y lanza la suya propia: una existencia itinerante, yendo él a buscar a los necesitados, a la oveja perdida, a reanimar los corazones desolados. El modelo que le proponen está montado sobre la dualidad estructural de salvador y salvados, dualidad que genera una instilución salvadora, a la cual acuden los que necesitan y desean algún lipo de salvación. El modelo de Jesús, en cambio, instaura una reciprocidad de dones: él, o sus discípulos, entran a las casas a comunicar la buena nueva del reino y a sacramentalizarla con el poder del Espíritu. La gente que les abre la puerta y que 
recibe su salvación les da, a su vez, su hospedaje como signo de la fraternidad de los hijos de Dios, que ya se está instaurando. En el primer modelo, tenemos una masa y una institución; en el segundo, el embrión de un pueblo, que va madurando, en el cual todos reciben y dan.

\section{La comunidad en función de la constitución escatológica del pueblo de Dios}

En este proyecto de Jesús, iqué lugar ocupa y qué papel juega la comunidad? Anle todo, comencemos por una constatación: tanto para Marcos $(1,16$ 29) como para Juan $(1,35-51)$, lo primero que hace Jesús es rodearse de un grupo de discípulos. La misión la lleva a cabo con ellos, lo que significa que el sujeto evangelizador es la comunidad de Jesús. Según Juan, los discípulos son los primeros del pueblo de Dios que lo reconocen como el mesías y también, por boca de Pedro, lo confiesan como mesías en los sinóplicos. Pero lo más caracterislico no consiste en esta confesión, sino en el seguimiento, un seguimiento que se va mostrando como incondicional y por el cual acabarán dejando la familia y la profesión, y pasan a constituir la familia de Jesús, quien a su vez lambién rompe con su familia (Mc 3, 31-35). Esto no quita que haya otros discípulos que no abandonan ni la familia, ni la profesión, aunque sí supeditan todo al seguimiento de Jesús (Lc 14, 25-27).

Este tipo de discipulado supone el reconocimiento del carácter escatológico de Jesús, de su propuesta y del tiempo que inslaura, ya que sólo desde el advenimiento de lo definitivo y, por tanto, de lo decisivo es posible relativizar lo más fundamental de la existencia humana. Así, pues, la comunidad de Jesús es la expresión sacramental de su propuesta escatológica. El que una comunidad así fuera viable, expresaría que el poder del futuro ya actúa, de algún modo, en el presente. La comunidad hace ver que lo de Jesús no es sólo algo nocional, sino un verdadero acontecimiento con fuerza para propagarse.

La comunidad de Jesús está, pues, en función del pueblo de Dios, de su constitución electiva como tal ("ustedes serán mi pueblo y yo seré su Dios", Jer 31, 33; Ez 36, 28; Ap 21, 3). Pero no al modo instrumental, produciéndolo de modo eficiente, por así decirlo, sino al modo sacramental, es decir, simbolizándolo de modo efectivo: siendo ya de una forma incoativa el pueblo de Dios, la comunidad lo despliega como crece un embrión. Con lodo, no es posible usar este símil organicista en forma mecánica, porque el Espíritu derramado en la pascua es libre con respecto a la comunidad cristiana concreta, ya que ese Espíritu está derramado sobre toda came (Jl 3, 1; Hech 2, 16-17). Se podría hablar, entonces, de una causalidad ejemplar, en el sentido más fuerte de la palabra (aunque tampoco se puede ignorar del todo la causalidad instrumensal, pues la misión no actúa por su propia eficacia, sino por la gracia de Dios, Rom 10, 14-18). La comunidad, pues, representa al pueblo escalológico de Dios, lo proclama como 
designio de Dios, lo produce con su visibilidad invitadora, lo sirve humilde y desprendidamente, sabiendo que el pueblo, como ella misma, no se pertenece a sí mismo sino a Dios y al Mesías Jesús. Así, pues, la comunidad constituye la primicia del pucblo de Dios, pero el pueblo de Dios la trasciende desde dentro, $y$, por eso, no puede dominarlo, sino que se pone de forma gozosa a su servicio.

\subsection{La comunidad lleva el nombre de Jesús}

Ahora bien, habiendo insistido en la transcendencia del Espírilu -que es capaz de sacar de las piedras hijos de Dios-, tenemos que volver a recalcar la pertenencia de la comunidad al misterio del Mesías Jesús. Es tan íntima esta pertenencia que el resucilado puede decir a Pablo que, cuando persigue de modo encamizado a la Iglesia, es a él a quien persigue. De esta revelación saca Pablo el símil de la comunidad como cuerpo de Cristo. Jesús resucitado ya no está aquí de forma factual (Mc 1, 6; Hech 1, 11); su visibilidad en la historia es la comunidad (Mt 18, 20;28, 20;10,40). También lo son los pobres (Mt 25, 40); pero en ellos es una presencia sin rostro, como la del siervo: no sólo no atrae, sino que provoca voltear el rostro para no dejarse afectar por ellos —aunque, en definitiva, de la actitud para con ellos depende el destino final. Lo específico de la presencia de Jesús en la comunidad es la presencia de su Nombre, y de tal manera que de la comunidad depende el que su nombre sea santificado (M1 6, 9; 18, 20; Jn 17, 6.26; Ez 36, 23). Cuando esto sucede, es decir, cuando la genle ve sus buenas obras y glorifica a su Padre, que está en el cielo (Mt 5,16 ), se da la evangelización: la gente se siente atraída a ese camino, a ese modo de vida. Y de entre ellos, aquellos a los que Dios llama, se sentirán movidos a entrar a la comunidad.

Que la comunidad sea la visibilidad de Jesús en la historia - junto con los evangelios- quiere decir que es la comunidad de los elegidos, de los que el Hijo ha consagrado con su sangre y, correspondientemente, de los que se han consagrado de forma libre a él, a llevar su nombre por todas las naciones, a través de la historia. La comunidad es habilitada para esta misión con el don del Espíritu, que está en su seno, pero es la responsabilidad de cada quien obedecerlo, o entristecerlo, y hasta apagarlo. De ahí, la exhortación a ser lo que somos, a secundar la obra de Dios, en uno mismo y en la comunidad. Este recordatorio tiene validez permanente, porque la comunidad lleva su tesoro en vasos de barro.

\subsection{Superación de la tentación sectaria}

Si la comunidad lleva el nombre del Mesías Jesús, no puede actuar en nombre propio, buscando su gloria, ni encerrarse sobre sí misma, anulando la salvación que expresa ese nombre. En los relatos evangélicos hay claros indicios de que, cuando Jesús se percató del rechazo de los jefes de Israel, habría sido tentado a concentrarse en la comunidad de los discípulos, enseñándoles sólo a 
ellos y abandonando el contacto abierto con las masas. Sin embargo, la decisión irrevocable de ir a Jerusalén expresa que Jesús vio incompatible con su misión reducirse al ámbito comunitario, y formar una comunidad de salvación separada del mundo, al modo, por ejemplo, de los esenios. Ni siquiera admitió la separación que practicaban los fariseos con respecto a los impuros, a los tenidos como pecadores públicos y a los que no conocen la ley, y, por ello, caían bajo la maldición de Dios.

La institución de los Doce expresa esła relación indestructible entre la comunidad y el pueblo de las doce tribus. Los Doce representan a las doce Iribus, pero no pueden sustituirlas, sino que están en lunción de ellas; es decir, están referidos a todo el pueblo de Dios que, tras el rechazo y la muerte y resurrección de Jesús, se compone de judíos y genliles, rasgado ya el velo que los separaba.

\section{Las comunidades, sujeto de la primera evangelización}

A la civilización de la ecumene helenista le pertenecía ser una red de ciudades en la que, como auténticas metrópolis con gran capacidad de irradiación, se encontraban algunas megalópolis como Roma, Alejandría o Antioquia. Es sabido que la evangelización de este ámbito cultural se llevó a cabo a través de una misión muy rápida que tenía como finalidad eslablecer en cada ciudad una comunidad cristiana. Al comienzo, esa misión no estaba planificada, sino que se debió a viajes fortuitos de cristianos o a la dispersión de la comunidad helenista de Jerusalén con motivo de la persecución, que cobró la vida de Esteban.

\subsection{Comunidades escatológicas y ausencia de estructuras religiosas tradi- cionales}

La primera misión sistemática de la cual tenemos noticia fue fruto de una decisión de la comunidad de Antioquía, comunidad que ofrecía la novedad radical de albergar en su seno a muchos venidos del paganismo, a quienes se anunció a Jesús sin pasar por la religión judía. Estos, que ya no practicaban ni la religión olimpica, ni las de los misterios, y que no se habian hecho prosélitos del judaísmo, aparecian ante los ojos de sus contemporáneos como un grupo paradójico: estaba consagrado a Dios, pero sin práctica religiosa alguna, a la cual, en aquella cultura, le era esencial la tríada templos-sacerdotes-sacrificios, de modo notorio ausente en esas comunidades. Y como se referían constantemente a Jesús como Mesías, los llarnaron mesiánicos, en griego cristianos.

Esta ausencia de estructuras religiosas convencionales es decisiva para nuestro tema, ya que con ello se daba la condición de posibilidad de que existieran auténticas comunidades. No eran como las fratrías, características de las polis griegas, que eran comunidades cerradas alrededor de un culto compartido, que no pocas veces tenía una base étnica o de vecindad (el demos). La comunidad la creaba y configuraba Jesús como Señor y paradigma de todos; la configuraba un 
sólo Dios Padre de Jesús, constituido por él en Padre también de todos; y el Espíritu que, al configurarlos en el Señor y hacerlos hijos de Dios, los hermanaba a todos entre sí. Esta realidad escatológica, definitiva, relativizaba todo lo demás. En la medida en que se decidieran a vivir esa novedad existencial, la diferencia entre judios (pueblo de Dios) y gentiles (no pueblo) quedaba anulada; y no menos las diferencias culturales de esclavos y libres, griegos y bárbaros, varones y mujeres. Claro está que subsistieron las diferencias, pero como las personas ya no se definen por ellas, tampoco son ya fuente de privilegio y discriminación.

Eslo significa que mientras la comunidad viva en esa tensión escatológica, es decir, dejándose configurar por ese fuluro que va operando ya dentro de ella, la comunidad liene una existencia densa, trascendente, que, por una parte, cuestiona a la sociedad por lo que tiene de contraste con ella, $y$, por otra, la atrae hacia esa alternativa superadora, que lleva en su seno.

$Y$ eso fue lo que sucedió. Durante los tres primeros siglos sobre todo, las comunidades trataron de hacer real esta novedad, transformando la mentalidad, la sensibilidad, las actitudes y el tipo de relaciones que sus miembros tenían entre sí, antes de convertirse al Mesías Jesús. La novedad, sin embargo, no podía consolidarse como mero almacenamiento, sino que tenía que recrearse siempre. Y la razón es clara: tanto el ambiente exterior, como mucho de lo que existe en el interior de las personas, tiende siempre a recortar la novedad. Esta no acaece en la medida en que los cristianos aclúan como miembros de los conjuntos ya dados (judíos-gentiles, griegos-bárbaros, libres-esclavos, varones-mujeres), sino sólo como dinamismo espiritual, aunque ese dinamismo puede llegar a convertirse en una especie de segunda naturaleza, y, así, a moldear los diversos ambientes. De todos modos, el elemento decisivo es la obediencia al Espírilu, el que con su dinamismo hace nuevas todas las cosas y renueva la faz de la ticrra.

\subsection{Comunidades que plenifican lo bueno existente}

Este dinarnismo fue real en medida suficientemente poderosa como para que, en las diversas ciudades, quedase planteada la renovación de la vida y de la cultura; y ello en dos direcciones: por una parte, como plenificación de lo bueno que ya exislía, y, por olra, como contraste.

La nueva vida era propuesta como plenificación de las mejores energías que latían en los corazones, en los ambientes y en los distintos estratos, bastante diferenciados, que componían el humus cultural. Así, Pablo podía exhortar a sus queridos filipenses: "todo lo que sea verdadero, todo lo respetable, todo lo justo, todo lo limpio, todo lo estimable, todo lo de buena fama, cualquier virtud o mérito que haya, eso ténganlo por suyo" (Fil 4, 8). Quisiera recalcar que esta actitud de ningún modo refleja el abandono de la expectativa escatológica y la adaptación a los paradigmas ambientales. Toda la carta está centrada, precisa- 
mente, en el día del Mesías Jesús $(1,6.10 ; 2,16)$, y en ella, Pablo define a los cristianos como "ciudadanos del cielo, de donde aguardamos como salvador al Señor Jesús, el Mesías" $(3,20)$. En este mundo, los cristianos somos los que estamos "en el bando de Cristo" $(1,29)$ y por eso tenemos que tener sus mismos sentimientos, su misma actitud $(2,5)$.

Pero siempre queda la pregunta: si el mundo da muerte a Jesús porque no lo conoce, ¿cómo es posible reconocer en ese mundo rasgos valiosos, que hay que considerar como nuestros? ¿Cómo es posible esa coincidencia, si no estruclural, sí al menos parcial, y no sólo fáclica, sino axiológica? La explicación estaria en la persona de Jesús, considerado como Hijo de hombre, es dccir, como alguien que puede ser caracterizado como un ser humano cabal (Dn 7, 2-14). Así como los imperios que se han sucedido en el dominio del mundo lienen hasla hoy el común denominador de un talante de ferocidad, y se han impuesto sobre los demás por la fuerza y por ella han mantenido su dominio, así aquel ser por el cual Dios va a realizar su soberanía en la historia tiene la característica de ser humano, y por tanto, tiene la virtualidad de humanizar. En eso consiste su señorío, que, por ello, no puede ser impuesto. $Y$ en ese horizonte hay que comprender las contraposiciones del sermón del monte (Mt 5, 21-48) como la universalización de una ley que se presenta como humanización integral, la gloriosa humanidad de los hijos de Dios. Esta humanidad, cuyo paradigma es Dios revelado como Padrc, es propuesta a los discípulos y a todo el pueblo (Mt 4, 25 - 5, 1-2).

Ahora bien, ¿cómo podía estar presente en el ambiente pagano este modo genuinamente humano de vivir, de manera que los cristianos pudieran reconocerlo como suyo? El prólogo de Juan responde que la Palabra, por la cual todo fue hecho, contenía vida y esa vida era la luz de los seres humanos $(1,3-4)$. $O$, en términos de la Carta a los Colosenses, por medio de él se creó el universo, él es modelo y fin del universo creado, él es antes que todo y el universo tiene en él su consistencia (1, 16-17).

Los padres de la lglesia, siguiendo este modo de pensar, dirán que los seres humanos hemos sido creados a imagen de la Imagen de Dios, Imagen que, como prototipo, ha impreso su impronta en cada ser humano, una impronta transcendente y que por eso no se puede perder. Esta impronla es luz, sentido y meta que alrac. Si ésta es la estructura transcendente humana, a pesar de lodas las desfiguraciones que deshumanizan, siempre se conservan algunos caminos de vida y valores genuinos, y siempre habrá personas que intentan con seriedad hacerlos realidad.

Esta será, precisamente, la dirección que animará el Espíritu derramado sobre toda carne en la pascua. Siendo Espírilu de vida, promueve, desde el inicio, el despliegue de la creación hacia su meta, aunque ahora aparece específicamente como animador de la vida fraterna de los hijos de Dios. Como el Espíritu no está constreñido por coordenadas espacio-temporales, cubre la redondez de la tierra y retrotrae la historia hasta Adán. 
Porque somos imágenes de Dios en su Imagen e hijos en el Hijo, la propuesta de Jesús pudo ser percibida por todos como evangelio, buena nueva. Es nueva, porque la Imagen y el Hijo son, precisamente, Jesús de Nazaret. Es buena, porque en él podemos ver realizado el sentido humano hacia el que caminamos, desde dentro de nosotros. Según esto, los evangelizadores cristianos podían apelar a todo lo que en el ambiente y en personas concretas había de obediencia victoriosa al Espiritu de humanidad, cuyo paradigma, sin nombre para sus oyentes, era Jesús de Nazaret. Así lo vio Pedro, respecto del centurión Cornelio, quien, siendo pagano, era acepto a Dios, porque era fiel y obraba con rectitud.

Esta intuición la explotaron ampliamente los apologetas y los padres de la Iglesia. En ellos existe la propensión que lleva a la aceplación de lodo lo humano y de su cultura - midiendo lo humano desde el paradigma de Jesús-, a la adopción, por parte de la comunidad cristiana, de todo lo tenido por noble y bueno, en la cultura ambiental. Esta propensión tiene dos vertientes. La primera, presente ya desde el comienzo, tiene que ver con la viabilidad del cristianismo: puesto que había divergencias irreconciliables con la propuesta cristiana vigente, había que encontrar puentes que hiciesen ver su papel de fermento humanizador en su medio, y, de este modo, su legitimidad. La segunda, más espúrea, tiene que ver con la protección imperial del crislianismo, que llega hasla proclamarlo como la única religión del imperio. La aceptación entusiasta de esta disposición, por parte de la jerarquía eclesiástica, hacia que, a la larga, luese muy difícil mantener la autonomía y la trascendencia, al proclamar los rasgos que caracterizan el modo humano de ser, que los cristianos proclaman como paradigma.

\subsection{Comunidades alternativas, pero no sectarias}

A pesar de lo dicho, en los escritos neotestamentarios a las comunidades cristianas se las caracteriza abrumadoramente más por contraste superador del modo de vida ambiental que por la plenificación de lo bueno, que ya se vivía en el abigarrado medio del imperio romano. Cierto es que los cristianos trabajan con sus manos, para no ser parásitos y para socorrer a los pobres (sobre todo los de las comunidades), que pagan los impuestos y respetan a las autoridades, e incluso que los esclavos tienen que obedecer a sus amos; y también es cierto que tienen que abstenerse de hacer mal a nadie y hasta tienen que devolver bien a quien les hace mal. Pero también es cierto que se distancian de los juegos y espectáculos públicos, porque, para ellos, estaban contaminados de idolatría, violencia e inmoralidad; que por las mismas razones se apartan en gran medida de la convivencia social, de modo que al vivir una vida comunitaria tan densa y de tal calidad pueden dar la impresión de que se dessolidarizan de la sociedad, despreciándola, dándola por perdida y buscando cómo salvarse de ella.

Hay muchas expresiones, aunque estén pensadas en otro contexto, que pueden dar pie para ser interpretadas, en ese senlido negativo. La visión tan pesi- 
mista del estado de corrupción generalizada en el imperio romano (Rom 1, 1832) lleva a Pablo a pedir a los cristianos - de modo general- que no se adapten a este mundo (Rom 12,2). De manera semejante, y muy pormenorizadamente, se insta a los efesios a que "no procedan como los paganos [...] que tienen su razón oscurecida [...] a causa del endurecimiento de su corazón; pues, encallecidos, se entregaron al desenfreno para obrar con avidez todo lipo de indecencias" $(4,17$ 19). "Tengan bien entendido que ningún fornicario ni avaro [lo que equivale a idólatra] ha de heredar el reino del Mesías y de Dios [...] No tengan parte alguna con ellos" $(5,5.7)$. A los filipenses les pide que "sean íntegros y sin malicia, hijos de Dios irreprensibles en medio de esla generación perversa y depravada" $(2,15)$. Pablo afirma que el mundo se le presenta como crucificado, es decir, como la figura más repelente e ignominiosa que podia existir, pero reconoce que así es también como aparece él a los ojos del mundo (Gal 6, 14).

Por eso, los cristianos fueron acusados con frecuencia (además de impiedad, por no practicar la religión en la forma convencional de templos, sacerdotes y sacrificios) de odio al género humano. Esta acusación nunca habría existido, si las comunidades cristianas no hubieran sido captadas como comunidades alternativas. Sin embargo, la atracción que suscitaban lleva a la conclusión de que, si podian provocar malestar, disgusto y resentimicnto por su efectivo distanciamiento de tantas prácticas y, más aún, actitudes, no había en ellas ni sectarismo, ni desapego, ni desprecio, sino un genuino afeclo, hecho a parles iguales de simpalía humana y de misericordia. La mayoría vivía esta vida alternaliva con humildad, porque reconocía en sí los mismos gérmenes de debilidad. Su vicloria sobre el mal la experimentaban como triunfo en ellos de la fuerza del resucitado, y, por eso, era motivo de agradecimiento. Pero, además, se sentian llamados a llevar la buena noticia de su nueva vida a todos, porque para todos había mucrto y resucitado Jesús, y Dios quería la salvación de todos. Por eso, mientras, por una parte, luchaban para no sucumbir a las tentaciones, tribulaciones y persecuciones, y fomenlaban la paciencia y la esperanza en la lucha, por otra, confiaban en la fuerza del evangelio para transformar su ambiente.

Sin tener en cuenta ambas cosas, una novedad real y una acogida efectiva, no se explica la irradiación de esas comunidades. La gente fue percibiendo en ellas una más alta realización humana, y que ese estadio superior de humanidad estaba realmente abierto a todos, fucra cual fuera el punto de partida. Eran comunidades alternativas, pero no elitistas, porque su humanidad palpitante estaba sustentada por la acción del Espíritu, por la fuerza de Dios, por el carácter ejemplar de la presencia viva de Jesús, y no menos por la ayuda mutua de las hermanas y los hermanos.

\subsection{Comunidades, presbíteros y gran comunidad}

Dos características que estimularon la forlaleza y la capacidad irradiadora de las comunidades cristianas fue la presencia en ellas de los presbíteros-epíscopos 
y el sentirse y saberse formando parte de una gran comunidad cristiana, germen del pueblo de Dios.

Cuando empezó a envejecer la generación de los discípulos que habían conocido al Señor - y más todavía la de los discípulos de éstos- se consolidaron dos cosas, que resultaron decisivas. La primera fue la puesta por escrito de las tradiciones que provenían de Jesús, con la recepción de otros escritos, más o menos ocasionales, dirigidos a comunidades particulares, en los cuales la comunidad cristiana reconoció su fe: el canon. Junlo a esos materiales nuevos, la Biblia hebrea fue aceptada y leída ahora desde Jesús. La segunda fue la constitución de los presbíleros-epíscopos, no ya para mantener el orden y supervisar la buena marcha de la comunidad (ésa era su principal función en las sinagogas y de ellas la tomaron las comunidades cristianas), sino sobre todo para velar por la transmisión fiel y creativa de la tradición, que se remontaba a Jesús. La constitución del canon y esla estructuración de las comunidades salvaron al cristianismo de su disolución ante el embate de los entusiastas, de los judaizantes y de los primeros broles de la gnosis.

Pero esta estructuración logró imponerse gracias a que nadie consideró a la Iglesia como una federación de comunidades, sino como la "primera" comunidad de la cual provenían las comunidades. Esta primera comunidad de los discípulos se designó simbólicamente como la comunidad de los Doce, porque representaba al pueblo de Israel y, tras la resurrección, a todos los pueblos dentro de él. Cada comunidad fundada por los primeros apóstoles y evangelizadores podía tener tradiciones particulares, pero acabaron reconociéndose mutuamente como formando parte de la riqueza común, que provenía de Jesús y sus discípulos, la comunidad escatológica que reunió Jesús para convocar definitivamente al pueblo de Dios. El punto culminante de la constitución del canon y de la ecumene católica consiste, por un lado, en la aceptación de las comunidades del discípulo amado de tradiciones y formas organizativas de la gran Iglesia, y, por otro, el reconocimiento, por parte de ésta, de los valiosos aportes de aquéllas.

Así fue como la comunidad que procedía del Señor Jesús se fue desplegando en comunidades vivas y arliculadas, que interactuaban entre sí de manera dinámica. En cada comunidad se realizaba, ciertamente, la Iglesia, pero ninguna pretendía totalizarla, ni monopolizarla, sirviendo de criterio único para las demás. Aun en el caso de la Iglesia de Roma, a la cual se asoció de modo paulatino el carisma de Pedro de confirmar a los hermanos en la fe, esa función se ejercía en la caridad fralema y en el respeto a la legítima variedad. Esa función, análoga a la que desempeñó al principio la Iglesia madre de Jerusalén, no entorpeció la actividad carismática de las iglesias, en las cuales se asentaba su talante comunitario. 


\section{5. ¿Conversión del imperio al cristianismo o conversión del cristianismo en religión imperial? Consecuencias para la comunidad}

En el siglo IV se pasa de la persecución a la proclamación del cristianismo como religión lícita, y de este ediclo de tolerancia a la protección abierta que acaba en la proclamación del cristianismo como la única religión del imperio. Este proceso suele ser interpretado de dos modos muy distintos. Para amplios sectores cristianos es el imperio el que reconoce la verdad del cristianismo y su capacidad para evitar su propia decadencia, mediante la conversión personal al Dios de Jesucristo, Dios de la humanidad, de la justicia, de la verdad y de la misericordia. Con la consagración del imperio a Dios y su entrada en la Iglesia se obtendría un cambio estruclural para propiciar la moralización de las costumbres, el ordenamiento de la vida familiar, la superación de la violencia y la crueldad, el establecimiento de la verdad, la con riabilidad, la justicia y la solidaridad. Hay que reconocer que este cambio se fue dando en una medida apreciable.

La otra versión, proveniente de sectores públicos, pensaba que los dioses tradicionales habían perdido la virtualidad de antaño, que ahora residía en Jesucristo; por tanto, a los sacerdotes cristianos se entregaba la función que hasta entonces habían desempeñado los colegios sacerdolales tradicionales. Naturalmente, eran los sacerdotes cristianos los que sabían qué había que hacer para obtener la protección divina del imperio. En todo caso, de eso era de lo que se trataba: el cristianismo quedaba convertido en la religión de la "ciudad y del mundo", de la res pública, una religión cívica, política, del Estado y de todos los ciudadanos. El culto cristiano tenía sus contenidos específicos, pero la nueva finalidad exigía también una nueva forma perfectamente objetivada y reglamentada para que el imperio pudiera estar seguro de la protección divina.

Desde esta perspectiva, la comunidad crisliana es la comunidad del imperio, y se empieza a equiparar ser ciudadano y ser cristiono. Esto significa diluir la sustancia de la comunidad. Además, si el objetivo de la religión es la salvación del imperio romano, desaparece la tensión escatológica y lodo se reduce a la preservación de lo existente con algunas mejoras posibles. Si la comunidad cristiana no es ya la levadura de la masa, sino la masa misma, la función que antes desempeñó para configurar el ambiente corresponde ahora a los sacerdotes, convertidos en clero. Ellos son ahora los pertenecientes al mundo de lo divino, los que ofician los misterios de los que participan los demás, pero ahora como asistentes. En esta interpretación del cristianismo no cabe la constitución de la Iglesia como comunidad escatológica portadora del Espírilu del resucitado, en marcha al encuentro con él. Ahora son los ciudadanos que se unen al mundo de lo divino por los actos de culto que efectúan los sacerdotes, separados de ellos. Se ha recaído en el dualismo del esquema religioso, en el cual no es posible la comunidad, sino que, por una parte, existen individuos y masa, y, por la otra, los especialistas, el cuerpo sacerdotal. 
Si nos preguntamos cuál de las dos interpretaciones hace juslicia a la realidad histórica, hay que responder que ambas, en diversos grados, según personas, lugares y tiempos. En si mismas, son incompatibles, pero, de hecho, convivieron y todavía conviven con las transformaciones del calso.

En principio, la cueslión quedó zanjada por el concilio Vaticano II. Insiste el concilio en la reescalologización de la comunidad cristiana, que es sacramento de salvación, en cuanto hace presente, en el hoy de la historia, el futuro de las promesas de Dios, realizadas ya en la persona de Jesús como nuestro primogénito; $y$, además, proclama la libertad de conciencia, lo que niega legitimidad a una comprensión del cristianismo como religión polílica. Esta declaración de liberlad religiosa es condición de posibilidad para la reescatologización de la comunidad crisliana. Sólo en la medida en que se reciban eslos elementos conciliares la Iglesia tendrá evangelio y la comunidad cristiana será su portadora.

\section{La comunidad, evangelizadora de las grandes ciudades}

De todo lo que hemos dicho hasta ahora podemos sacar una importante lección para la evangelización de las grandes ciudades, en el mundo de hoy: la comunidad cristiana es sujeto evangelizador de las grandes ciudades, a condición de que no se conciba como una comunidad civil, que fuese expresión religiosa del peso, es decir, de la gloria, la grandeza de la ciudad, sino que se conciba como comunidad escatológica, es decir, que, por la presencia del Espíritu en ella, se atreve a sacramentalizar la presencia y la prestancia del futuro, en el presente. Nos referimos, específicamente, al fuluro que abren las promesas de Dios, que se pueden sintelizar en los bienes mesiánicos o en el reino de Dios. Este fue el horizonte en el cual vivió Jesús y que hizo presente con su palabra de autoridad y con la fuerza de sus acciones liberadoras. A este horizonte, así anticipado, pidió Jesús que se convirtieran los que lo escuchaban. Era posible abrirse a él, porque el propio Jesús atraía con su presencia alentadora. El que Dios lo resucitara significa que ya ha comenzado la transformación de los últimos tiempos. Jesús es ya un ser humano completamente espiritual, es decir, capaz de vivificar, porque vive la vida de Dios.

Hagamos ahora algunas reflexiones que ayuden a llevar a cabo la evangelización hoy en las grandes ciudades.

\subsection{El mundo de las corporaciones, negación de la comunidad y la espe- ranza}

Vivimos en el imperio de las corporaciones mundializadas. Esta figura histórica ha producido bienes civilizatorios y culturales tan valiosos que, sin ellos, no puede vivir la humanidad. Es claro que la evangelización de las grandes ciudades debe apoyarse en ellos. Pero mientras las corporaciones dominen - sin algún contrapeso eficaz-, imponiendo sus intereses y su lógica, esos bienes no 
darán de sí lo positivo que deben dar, y se impondrá, por el contrario, la exclusión de las mayorías, la deshumanización de los que las excluyen y la falta de medios de vida de los excluidos. De ahí que la evangelización de las grandes ciudades tiene que tener en cuenta el desafío de las comoraciones, que son cl sujeto dominante, en nuestro mundo. Ellas imponen un horizonte de individualismo, de insensibilidad y de resignación a la realidad, y, sobre todo, un horizonte y una lógica social.

Individualismo no significa aquí rasgo de carácter, sino la negación de que los seres humanos somos estrucluralmente respectivos y que, por tanto, sólo hacemos justicia a la realidad oplando por la pertenencia a las comunidades que nos constituyen y constituimos: ante todo a la comunidad humana como un todo real y a la familia de la cual provenimos y en la cual nos socializamos, al pueblo del cual formamos parte, al Estado del cual somos ciudadanos, a la ciudad donde residimos, a las comunidades laborales, vecinales, políticas y a otras de nuestra elección. Individualismo significa comprendernos como individuos, de tal manera que lo demás no nos constituye, sino que es secundario, algo previo o circunstancial, que sólo esıá en función de los individuos. En otras palabras, individualismo significa negar que formamos parte de la realidad histórica, es decir, que provenimos de otros seres humanos y somos origen de otros, y que esta constitución concrela nos posibilita y es fuente de responsabilidades, es decir, orienta nuestra creatividad histórica para que sobre ella se ejercite nuestra libertad de manera consiructiva. Individualismo es vivir en el presenle y en sus proyecciones, en un presente que hace abstracción de los que vivieron antes y de los que vivirán después. Significa vivir según las preferencias individuales.

Además, el horizonte que imponen las corporaciones es, obviamente, un horizonte de mercancías, siempre renovado. Las mercancías no son cosas, digamos, desnudas, sino productos asociados de manera mágica a pulsiones, descos y sueños, a un mundo apetecible y prestigioso, al mundo de los triunfadores, que viene a equivaler a la comunidad virtual de los consumidores. Para acceder a ese mundo, y a la constelación de vida y sentido del cual forma parte, hay que aceptar la lógica de la competitividad para prevalecer sobre los demás, en la lucha sin cuartel del mercado; es decir, la lógica del individualismo.

\subsection{Anticipar el futuro: vencer la desesperanza de fuera y el pecado de dentro}

Esle horizonte de las corporaciones exige renunciar a la esperanza de construir el mundo fraterno de los hijos de Dios, la esperanza de un mundo en el cual la carrera armamentista se trasforme en trabajo biófilo y ecológico, en el cual la explotación del hombre por el hombre dé paso a la colaboración y la emulación en el servicio, en el cual la diversidad de pueblos y culturas se asuma como riqueza mutua superando la exclusión, en el cual la autosuficiencia orgu- 
Ilosa ceda el campo a la adoración libre y agradecida al Creador y Padre de todos.

Esta esperanza, fundada en la promesa de Dios, es proclamada por la comunidad cristiana no sólo como ulopía -irrealizable-, sólo útil en cuanto genera ilusión y ánimo y hace las veces de un referente ideal, sino también como principio de actuar ya en el presente. En un mundo de lobos, la comunidad vive en la fratemidad; en un mundo violento, vive desarmada; en un mundo cosilicado y reducido a mercancía y a desecho vive en sobriedad y amonía simbiólica. En un mundo reiterativo de pretendidas novedades, que no son sino repeticiones camulladas o variaciones sobre el mismo tema o desarrollo de lo ya dado, la comunidad apuesta por la creación histórica, la concibe de forma imaginaliva, la gesta con paciencia y la va dando a luz con dolores de parlo; en este mundo que desconoce al otro y lo excluye, la comunidad está dirigida a la inclusión y al reconocimiento; en este mundo sin lidelidades la comunidad vive religada al Dios de Jesucristo y echa la suerte de manera responsable con la realidad histórica.

La comunidad cristiana lo es en cuanto cree que este futuro de Dios actúa ya con fuerza en el presente, posibilitando en él la novedad de vida, que consiste en vivir según el paradigma de Jesús. En cuanto la comunidad se deja configurar por la atracción del crucificado resucitado $(\mathrm{Jn} 12,32)$ y por la fuerza del Espíritu que él nos entregó, en cuanto vive de la fe que libera del egoísmo esclavizante y vence al mundo, existe como una realidad cualitativa, como sacramento de la salvación, que Dios obra por Jesús.

Mientras vivamos en cste mundo, no podemos superar definitivamente el pecado. Por ello, el testimonio de la comunidad está oscurecido por el ejercicio del dominio sobre los hermanos, por el desprecio de los pobres, por la hipocresía, por las rivalidades que generan bandos y hostilidad, por el apego al bieneslar y la resignación ante la mediocridad. Siempre habrá pecado en la comunidad cristiana, pero dejaria de ser tal, si se resignara al pecado y, peor aún, si ni siquiera lo reconociera. La comunidad es crisliana siempre que se levante, una y olra vez, de su caída, luche por superar todo lo que la lleva al pecado, lo cubra con el ejercicio de la caridad y sepa incluso sacar bien de su propio mal, humillándose. llenándose de misericordia y transformando la experiencia en sabiduría. Pero es sobre todo cristiana cuando ni siquiera su pecado le quila la capacidad de imaginar un mundo más humano y la esperanza de que llegará a vivir en ese mundo. La esperanza de que es posible la conversión y la transformación.

Esa esperanza, la referencia real a un mundo donde habite la justicia, la sinceridad, la honradez, el reconocimiento mutuo, la alegría de vivir y de convivir. En suma, el mundo fraterno de los hijos de Dios, es lo que nunca puede perder la comunidad. Vivir a la espera de algo, ya es vivir con un referente concreto; pero vivir con esperanza es predisponerse activamente a lo que se 
espera, prepararse para lo que viene, ir haciéndole lugar en el presente. Se nos pide, pues, dejarnos afectar por ese mundo nuevo, desearlo, imaginarlo, cantarlo, rumiarlo en el corazón hasta ser poseídos por él, y dar pasos hacia él, hasta llegar a pertenecer a él, aunque ninguna figura histórica lo puede ofrecer.

\section{Esperanza y desinstalación}

La comunidad no puede cultivar esta esperanza y testimoniarla como su evangelio si está instalada en la realidad vigente, sea porque se siente, de hecho, moldeada por ella y se aprovecha de ella, sea porque, aunque la padece, se ha resignado a vivir con ella. Pero si la comunidad se ha entregado a la figura histórica vigente, ya no liene evangelio. Su dios y su mesías aprobarán lo que comenzó y está ahora consolidado (el dólar lo proclama emblemáticamente: Dios aprobó lo emprendido —onnuil coeptis-, es decir, el novus ordo saeculorum —el nuevo orden de los tiempos-), o, como no pueden competir con ese nuevo orden, se reducirán a consolar, de forma compensatoria, a sus creyentes.

Tal vez, el cambio cultural más fuerte respecto de hace algunas décadas es que, entonces, muchas personas eran capaces de pensar una figura histórica altemativa, un nuevo orden económico internacional, lo que requería un serio ejercicio político y un cambio cultural (de hábilos, expectalivas, valores...). Pensar una figura hisı́orica distinta llevó a diseñar proyeclos históricos y a emprender acciones concretas, en muy diversos frentes. Hoy, el dominio político de las corporaciones transnacionales se consolida gracias a su dominio ideológico y a su capacidad de diseñar el imaginario vigente y cooptar así a las masas. En la medida en que soñamos los sueños que ellas han proyectado para nosotros, y nos los sirven enlatados, no sólo nos tienen en su poder, sino que somos hechura suya.

Si los miembros de la comunidad se dejan configurar por esa ideología, su identidad cristiana no pasa de ser algo ancestral, sagrado e intocable, arcano y separado del resto de la sociedad; por eso, renuncia a configurarla. O la asume como algo puramente compensatorio ante tanta vaciedad, tedio, degradación y, muchas veces, penuria vital.

\subsection{Evangelizar, escatologizar, el cristianismo como experiencia de lo sa- grado}

En el primer caso - separación del resto de la sociedad-, la comunidad cristiana se hace real sobre todo en el ámbito litúrgico, en el cual tiene lugar el contacto con el mundo transhistórico, el mundo que otorga peso, equilibrio, identidad y sentido de dignidad. En la vida real, esa comunidad pasa a ser una especie de comunidad virtual. Sus miembros se comprenden en cuanto referidos al mundo sagrado. Eso los lleva a cumplir con las reglas establecidas con cierta resignación y sobriedad, cuidando de no cometer como individuos, actos en contra de los mandamientos - aunque tampoco consideren que hay responsabi- 
lidad moral en seguir la lógica del mercado, pues sus leyes no dependen de uno, $y$, si no se las acata, la competencia acaba con uno. Este tipo de comunidad no se da sólo en clases altas y medias, sino también en los sectores populares, presas del sisterna, atados por créditos para la vivienda, y que aspiran a la estabilidad del empleo y del sistema en general. Es una comunidad que goza de gran estabilidad, ya que en ella están cifrados sus deseos y la satisfacción de sus necesidades vitales. Pero, por eso mismo, no tiene ni evangelio, ni esperanza. La salvación aconteció en el pasado, $y$ hoy uno se adhiere a ella en la liturgia y en el comportamiento moral, y se espera participar de ella, definitivamente, en la otra vida. Esta concepción de salvación y del modo de participar en ella no genera comunidad de vida, interacción humana, fraternidad histórica. La salvación es cosa individual. La comunidad que se aprecia y se necesita para la reafirmación es una especie de reconocimiento casi tácito de que en ella se está en lo mismo de siempre. Pero nada más.

Sin embargo, no hay que despreciar ese modo de vivir el cristianismo. Es cierto que, a veces, se busca en ello el sentido de la vida con independencia de cualquier compromiso histórico e incluso de cualquier estilo de vida, pero eso ocurre sobre lodo en clases adineradas bienpensantes. Es una deformación y no hace justicia a la religación con lo divino, no por arcana menos real, que muchos contemporáneos de países tradicionalmente cristianos no quieren perder de ningún modo, sino que la estiman y cultivan a su modo, sobre todo en los tiempos litúrgicos fuertes, en las fiestas locales y, de forma más personal, en los ritos importantes de la vida: ingreso a la comunidad, adolescencia, matrimonio, enfermedad, muerte. $Y$ hay que hacer notar que el sentido de pertenencia a ese mundo arcano y, a la vez, a esa comunidad diluida, pero real, de los que aceptan esa misma religación ha resistido incólume el embate de la secularización. El fenómeno no puede comprenderse como pura rutina. En él ha intervenido la decisión libre de varias generaciones, en un ambiente muchas veces no sólo de emancipación de la autoridad eclesiástica, sino de virulenta reacción ambiental, en contra del autorilarismo eclesiástico, padecido secularmente y todavía no superado en la práclica.

Esta opción por la religación con lo sagrado, más o menos consciente, pero real, a través de los ritos cristianos y de la moral de los mandamientos debe ser valorada, al menos, como el pábilo que aún humea y que los responsables en la Iglesia, y todos los cristianos con responsabilidad hacia ella, deben contribuir a reanimar, siguiendo la misión del siervo, que Mateo atribuye a Jesús $(12,17-$ 21). Es cierto que no se trata todavía de la esperanza escatológica que hace nacer a una Iglesia sacramento de salvación, pero sí es, al menos, principio de transcendencia con respecto al totalitarismo de la ley de hierro del mercado. No tiene peso suficiente como para emanciparse de esa ley, pero sirve, al menos, para mantener otro referente, más primordial y fundante, que impide sucumbir completamente a la lógica del mercado, perdiendo la propia dignidad. 
Si la comunidad concreta y sus responsables comprenden dentro de toda la comunidad cristiana, es decir, de todo el pueblo de Dios, el modo de evangelizar el tipo de religiosidad descrito, debe partir del reconocimiento de la legitimidad de sus demandas, y, más aún, de su sentido de pertenencia, es decir, de su derecho a habitar en "la casa", que es el pueblo de Dios. Ellos son cristianos por la gracia de Dios y por su libre y peculiar respuesta a ella; no son crislianos por la gracia de ningún jerarca. Ellos tienen que sentir que son aceptados como miembros “de casa”, a quienes ni se les hace ninguna concesión, ni se les cobra ningún peaje, ya que la Iglesia es tan suya como lo es del cura. Este está al servicio de su fe, alimentarla y canalizarla de manera constructiva. El no es el dueño que pone las normas, de acuerdo a su criterio o conveniencia. Si hemos insistido en que esta gente mantiene su lazo de unión como un acto de libertad entrañable, en el cual se unen el acatamiento al misterio y el sentido, incluso el gusto, por la amistad, es porque espera que se le acoja en esos mismos términos. Nada espanta tanto como una relación meramente burocrática, o el aprovecharse de otros para indoctrinar y mantener así la autoafirmación institucional. En lugar del encuentro deseado, ocurre entonces un desencuentro, que provoca desafecto y resentimiento.

Para que la gente se relacione efectivamente con la transcendencia, es lambién imprescindible que se mantenga el tono simbólico. Lo que en la comunidad hay de palabra tiene que percibirse como proveniente del más allá. Sólo entonces se aceptará lo que la palabra tiene de exigencia, porque es la exigencia de aquello que enraíza y da vida, y por eso liene autoridad y se capla como saludable, aunque también ocasione sufrimiento.

Si la comunidad cristiana cultiva, en verdad, una genuina esperanza escatológica, entonces, sí es bien posible que la anuncie a partir de la noción de transcendencia, que mantiene este tipo de cristianos, con tal de que la proponga como realmente transcendente, es decir, fundada en la promesa de Dios, y no como pretensión humana o sacralización de un optimismo histórico. Para lograrlo debe aparecer como horizonte que atrae y no como obligación; debe estar ofrecida a la imaginación, al deseo, al querer, y no impuesıa como ley para poder ser cristiano.

De lodos modos, también hay que reconocer la contradicción objetiva entre esta religación ancestral y el dejarse configurar por el mundo actual, en lo que tiene de destrucción de lazos humanos, al entregarse a la competencia como norma suprema y al consumo como realización vital. Esta contradicción no se resuelve separando religación y mercado en ámbilos eslancos, sino sólo confinando a éste en su campo, limitando políticamente sus deformaciones y arbitrando esferas densas de sinergia y solidaridad. Esto significa que, en la medida en que se toma en serio la religación con lo sagrado, al menos como lo concibe el cristianismo, por congruencia con ella siempre habrá que dar un aporte a estas transformaciones. 


\subsection{Evangelizar -escatologizar- la vivencia compensatoria del cristianis- mo}

La vivencia compensaloria del cristianismo es muy diversa, dependiendo, fundamentalmente, de dos variables. La primera es si se vive desde los vencedores o desde los perdedores, en el juego de la competencia aclual. La segunda es si se liene conciencia de la deshumanización que produce en la propia persona el entregarse a ese juego o si sólo se percibe su insuficiencia y el desgaste que produce.

Si se trata de alguien que, de alguna forma, podemos llamar un triunfador, la vivencia cristiana será escasa; más que una compensación será un complemento de sentido o de experiencia. La propuesta de un horizonte escatológico no lo atrae, porque su reino está en este mundo; vivir de manera novedosa le suena a innecesario, porque está, en lo fundamental, satisfecho, y también le parece inconveniente, porque arriesga demasiado por algo cuyo sentido y conveniencia no le parecen claros. Una persona así con dificultad puede captar la propuesta cristiana, aunque de todos modos sí se le debe ofrecer la alegría que conlleva el reconocer a los demás como hermanos y el ser reconocido por ellos; $y$, por consiguiente, el dedicar esfuerzos y creatividad para incluir a los excluidos de la vida.

No es rácil que el vencedor dé este paso, si no ha senlido antes la miseria humana, que supone entregarse al juego establecido por las corporaciones. Por eso, quienes van cayendo en la cuenta de ello ya han adquirido lo más importante. A estas personas no les ayudan ni comunidades rigoristas, que convierten en angustia ese sentido de su propia realidad y así lo reducen al ámbilo subjetivo del superego y con ello impiden que sea procesado superadoramente; ni comunidades militantes, que exigen a destiempo resoluciones sumamente serias. Con ello impiden que se produzcan procesos auténticamente personales, conversiones humanizantes, que potencian lo mejor de esas personas y minimizan los males. Las comunidades que sí viven de la esperanza escatológica ayudan a estas personas a vivir la tensión entre la deshumanización sentida y la nueva humanidad -expresada en Jesús-, que se anhela. Esla tensión no destroza a la persona, sino que la pone en camino de superación, basado en la fuerza del Espíritu.

Desde los perdedores es más fácil captar lo deshumanizante del juego de las corporaciones. Por un parte, casi no les queda sino sobrevivir, y por ello a amplios sectores populares les parecen muy positivas las oportunidades para cualificarse y hacerse compelitivos; y no pocos, a través de esfuerzos muy costosos, van realizando bastantes progresos. Pero por otra, captan que tienen pocas oportunidades, enormes desventajas, y que tal como funciona el mercado las reglas del juego no les favorecen. Sin embargo, muchas de estas personas no ven otra posibilidad, sienten que no tienen más remedio que resignarse a lo dado. Incluso han llegado a la conclusión de que así es la vida, y que lo mejor es aceptar las pequeñas oportunidades y el sucedáneo de vida que ofrece el 
televisor, con la ilusión que genera de pertenecer a una comunidad virtual de muchos, que viven de igual manera.

Para estas personas, el cristianismo sí puede llegar a ser una compensación importante. Al evangelizarlos, lo fundamental es propiciar experiencias cada vez más hondas y verdaderas, en relación con la transcendencia. Dios y Jesús tienen fe en ellos y los llaman a entablar relaciones de confianza; más aún, los llaman a que se entreguen en alianza incondicional. Hay que propiciar también experiencias con la propia comunidad que los acoge con el mismo respeto y gratuidad que Dios. Lo fundamental aquí es generar un proceso, de modo que conciban posibilidades vitales distintas y las vayan poniendo en práctica, en la comunidad fraternal, donde pueden vislumbrar olro horizonte: el que instaura el Dios de Jesús con su acercamiento y con la fe que tiene en nosolros, y la presencia de su Espíritu, que muestra caminos y anuncia promesas.

\subsection{Una buena noticia: en la ciudad hay Espíritu}

La comunidad cristiana no es el ámbito de los predestinados, ni una institución religiosa particular. Se autocomprende como sacramento de salvación. Evangeliza a la ciudad, cuando anuncia que también en ella alienta el Espíritu de Dios y se pone a su servicio. No tiene mejor buena noticia que anunciar a la ciudad que su Dios, el Dios de Jesús, actúa en ella, que no es un ámbito profano, ajeno a la presencia salvadora de Dios, carente de significado transcendente. No es la Iglesia, ni ninguna otra institución religiosa, la que, en definitiva, lleva la salvación a la ciudad. En ella se juega el destino humano, y no sólo el de cada ser humano, sino el de cada generación.

$\mathrm{Y}$ sin embargo, aunque la Iglesia no es una realidad absoluta a la cual la ciudad tiene que remitirse, tampoco la ciudad, su estructura, sus instituciones, sus ordenanzas, sus organizaciones y personeros, dan la medida de su salvación. Por el contrario, ésta debe ser medida por lo que la ciudad debe propiciar: el desarrollo humano de los ciudadanos, que sólo puede concebirse como desarrollo dentro de toda la humanidad. La ciudad no es ni la suma alealoria de individuos, ni un colectivo totalitario. El Espíritu que mueve la evolución creadora lleva a la constitución de núcleos personalizados cada vez más densos, es decir, más conscientes de sí y más capaces de autodeterminarse libremente, y mueve también a la interacción cada vez más estrecha de esos núcleos.

Los bienes civilizatorios de la actual figura histórica permiten esta interacción, horizontal, simbiótica y personalizadora. Y sus bienes culturales (cultura de la democracia, de los derechos humanos, de la vida) la fomentan. Sin embargo, las corporaciones transacionales se esfuerzan por todos los medios en convertir esta posibilidad de diálogo enriquecedor en mercancía, en reducir todos los derechos al de la libertad, y, a ésta, a libertad económica, entendida como el único contenido de la democracia, que debe ser salvaguardado y apoya- 
do por el Estado. Desde este punto de vista, la gran ciudad es el espacio óptimo para que se interconecte un aparato productivo extremadamente complejo y un mercado suficientemente vasto, junto con una comunidad científico-técnica, que garantice la constante innovación tecnológica. La producción material de la vida y su organización social, así como el consumo muy diversificado, posibilitan un ingente volumen de negocios que se alimentan mutuamentc. Pero si prevalecc este punto de vista, no se genera desarrollo humano. Por eso, según la ideología que está detrás de este proyecto, el desarrollo humano no puede ni debe ser el objetivo de la ciudad, ya que esto es un asunto que concierne sólo a quienes se lo plantean.

Por el contrario, la comunidad cristiana sí cree que el objetivo de la ciudad es el desartollo humano y, por tanto, lo que legitima sus instituciones y esiructuras. Más aún, proclama que esta convicción nace de su fe en Dios como creador de la humanidad y del designio divino, que es el mundo fraterno de los hijos de Dios. La comunidad proclama que cste designio ya ha empezado a cumplirse en Jesús, quien vive en Dios como primicia de la humanidad.

\subsection{La comunidad, sacramento de la fuerza del futuro, en el presente}

Decíamos que lo primero que proclama la comunidad es su esperanza, basada en la promesa de Dios, que en Jesús ya ha comenzado a tener su cumplimiento. Así como Pablo decía a los corintios que si los muertos no resucitan, él y los cristianos eran unos ilusos o unos embaucadores al anunciar la resurrección de Jesús, así nosotros podemos decir que si el ser humano es un lobo para el hombre y la humanidad un campo de lucha en el que prevalece el más fuerte, Jesús no es el primogénito de muchos hermanos y la humanidad no va a llegar a ser, un día, el mundo fraterno de los hijos de Dios.

Pero, así como para Pablo la proclamación de Jesús resucilado no depende de la creencia en la doctrina de la resurrección universal, sino de que Jesús se dejó ver como resucitado - y así lo aliman los tesligos-, de la misma manera, la proclamación de Jesús como primicia de la humanidad salvada y reconciliada, no se basa en una concepción antropológica, sino en que Jesús, cuando se apareció a los discípulos, no les echó en cara su abandono, sino que los convocó, nuevamente, como el hermano mayor (Jn 20,17) y les envió su Espíritu para que formaran un solo cuerpo. Más aún, ese Espíritu abolirá en la comunidad los antagonismos de judío-gentil, libre-esclavo, griego-bárbaro, varón-mujer, de modo que la diferencia no conlleve discriminación.

Así, pues, la comunidad cristiana es el argumento y la garantía de que Jesús, en la cruz, ha reconciliado a los seres humanos, con Dios y entre ellos, posibilitándoles el perdón mutuo, el cambio de mentalidad y de actitudes, la victoria sobre el egoísmo individual y colectivo, el reconocimiento de los otros individuos y culturas como riqueza, y el establecimiento de la convivialidad fraterna y 
la sinergia en la creación histórica. Si en un momento determinado, no ocurriera nada de esto, en ese momento, Jesús no sería ya cl Señor, pues lo es en cuanto primogénilo de los hermanos.

La comunidad crisliania es la que lleva el nombre de Jesús, y si de ella desapareciera la fraternidad, tampoco sería santificado ese nombre. Por eso, la glorificación que Dios hace de su Hijo Jesús incluye que nunca falte la fraternidad entre los que llevan su nombre (Fil 2, 9-11; Jn 17, 20-23). Ahora bicn, esa fidelidad vicloriosa del Espíritu fraterno del crucificado resucitado no está garantizada por ninguna realidad institucional. Ocurre cuando ocurre, no en base a ninguna institución o estruclura. Y esto se aplica incluso a la eucaristía, como lo testimonian los dos textos del Nuevo Testamento que condenan la estructura dia-bólica, no sim-bólica, de la celebración, porque desune y rompe la fratemidad (1Cor 11, 17-22; St 2, 1-9).

De aquí se deduce que la esperanza que proclama la comunidad cristiana no está meramente remitida al futuro. No proclama sólo el designio de Dios de que la humanidad creada por él no fracasará, sino que llegará a la plenitud; ni siquiera proclama sólo que esa esperanza está realizada en Jesús. Los cristianos proclamamos que ese futuro (que ya es presente para Jesús) aclúa ya en nuestra historia. Proclamamos que actúa en toda la humanidad, porque el Espiritu ha sido derramado sobre toda carne. Y también testimoniamos que actúa en nosoIros, en la comunidad cristiana, renovándonos y constituyéndonos en comunidad reconciliada y dinamizada. Si la Iglesia renuncia a este testimonio, su mensaje es vacío. En este sentido, la comunidad cristiana es escatológica: ha sido constituida para testimoniar la fuerza del futuro de Dios, en este mundo y en esta carne, y en particular, en ella misma. Evangeliza a la ciudad, en cuanto es capaz de señalar dentro de ella ese paso del Espíritu, generando un desarrollo humano, según el paradigma de Jesús.

\subsection{Evangelizarnos es constituirnos en comunidad}

Esta visibilidad de la salvación, en la comunidad cristiana, es el reto que tiene que afrontar la Iglesia para constituirse en sujeto evangelizador, en las grandes ciudades. En este sentido, Juan Pablo II viene insisliendo reiteradamente $-\mathrm{y}$ nos lo ha dicho en particular a nosotros, en Ecclesia in America- que, para evangelizar, la Iglesia tiene que evangelizarse a sí misma. Pues bien, un fruto de esta evangelización, que no puede faltar, es la constitución de la Iglesia como comunidad y también la constitución de una red de comunidades denlro de toda la Iglesia. El que los miembros de la institución eclesiástica dejen de definirse como tales, sean, ante todo, parte del pueblo de Dios y entablen con los demás cristianos relaciones de convocados y condiscípulos; correspondientemente, el que los demás, laicos y laicas, dejen de comprenderse a sí mismos como particulares que van a la iglesia sólo a buscar su provecho y conveniencia, 
y lleguen a aceplarse como hermanos que se llevan mutuamenle; eso es no sólo condición de posibilidad para evangelizar la ciudad, sino que es ya evangelio. Si no todo él, sí una parte imprescindible.

Por eso, la pregunta crucial es, ilenemos tanta fe los cristianos de las grandes ciudades que nos empeñamos siempre en constituimos en comunidad y comunidades? Nosotros, que, como el resto de nuestros conciudadanos, sentimos la fuerza del individualismo ambiental, ¿creemos en la fuerza mayor Jel Espiritu, que nos estimula a vivir en el seguimiento de Jesús como familia de Dios?

No pocos preferirían poner la evangelización en manos de especialistas en mercadeo, camino que parece menos desmesurado, más productivo y no tan exigente y desgastante. $Y$ sin embargo, Jesús concibió su misión como un movimiento de unión, que exigía, sí, transformación personal y social, pero que era posibilitado por la fuerza del Espíritu. Si le quiere ser fiel, la Iglesia no puede pensar otro modo de evangelizar, que sería más planificado y previsible, pero menos costoso y comprometido. Habrá que poner mucho cuidado en pensar la comunidad cristiana adecuadamente, pero no proclamaremos el evangelio de Jesús si renunciamos a constituirnos en comunidad.

\subsection{Comunidad cristiana y comunidades cristianas}

Después de todo lo dicho, vamos a tratar de precisar un poco más qué entendemos por comunidad cristiana. La comunidad existe en el reconocer a los demás como cristianos, lo cual es algo denso, entraña un vínculo de simpalía, de afinidad, de "andar en lo mismo". Esto presupone que, para cada uno, "ser cristiano" es algo relevante y de alguna manera definitorio. Si la referencia a Jesús y al reino es un eje fundamental, incluso el eje decisivo, que mueve y da sentido a la vida de los crislianos, es claro que, cuando por cualquier circunstancia se encuentran, tienen mucho que compartir y sienten que los une un vínculo muy íntimo. Si, además, se sienten convocados para la misma misión con respeclo a la ciudad, se reconocerán también como copartícipes de una misma responsabilidad - son colaboradores. Por último, si se sienten movidos por el mismo Espíritu, es muy posible que, al encontrase y escucharse en foros, eventos o tareas, lleguen a percibir un aire de familia, es decir, se reconocerán como cristianos. La comunidad en cuanto tal se va haciendo, constiluyendo. No se encuentra sólo ni principalmente en actos de masas, aunque las masas sean cristianas, sino que se encuentra sobre todo en la ciudad. La comunidad acontece en el reconocerse.

Las comunidades son unidades de base, los lugares en donde habitualmente cada cristiano alimenta su fe y confirma la fe de otros, donde se ayudan muluamente, en su vida cristiana. Las comunidades, que se suelen llamar a sí mismas - cada una de ellas- simplemente "comunidad", son la célula mínima de eclesialidad. No pueden ser tan grandes que no sean manejables y dificulten las funciones mencionadas, pero tampoco pueden ser tan pequeñas que no puedan 
garantizarlas. Esto último suele ser un problema bien real en las comunidades. La pequeñez las lleva a vivir un tanto forzadamente, a adoptar direcciones que son unilaterales, a causa del talante dominante - no pocas veces a convertirse en secta o a desaparecer.

\subsection{El evangelio consiste en que el Espíritu actúa en la debilidad}

El secreto de las comunidades es comprender bien que son creación del Espíritu. Esto significa que son puro aconlecimienlo. Por supuesto que en ellas se dan los elementos societarios por los cuales es reconocible cualquier comunidad, pero no está en ellos la transcendencia que las convierte en sacramentos de salvación. La Iranscendencia está en lo que las comunidades tienen de aconlecimiento vivo. El Espíritu, por decirlo de modo simbólico, es verbo, no sustantivo. El Espíritu no se encama -y se desmoviliza—, sólo acontece. Dejadas a sí mismas, las comunidades tienden a la rutina o, por el contrario, a hacerse elitistas; en todo caso, a cerrarse sobre sí mismas, viviendo autárquicamente o entablando con el exterior unas relaciones que expresan separación. Pero cuando se da la obediencia al Espírilu, aconlece a la vez la transformación personal, según el paradigma de Jesús, las relaciones verdaderamente fraternas y el echar la suerte con los conciudadanos, en especial los pobres y los que sufren. Esta obediencia no es algo que se almacena, ha de hacerse siempre aconlecimiento, en el presente. Puede llegar a convertirse en rutina, incluso en una segunda naturaleza; pero nunca puede llegar a convertirse en pura naturaleza, como si las personas y la comunidad pudieran apropiarse de esas actiludes. Si eso sucede, ya no es obediencia, ya no hay Espiritu.

Todo esto quiere decir que las comunidades no son escatológicas, obviamente, por sus elementos socioculturales. La transcendencia se da en la obediencia al Espiritu, que revolotea en ellas, sabiendo que también en ellas se da la debilidad, la autoafirmación orgullosa y la adaptación a lo que la situación tiene de limitado y discriminador. Así, pues, los integrantes de las comunidades y las comunidades como tales tienen la audacia de sacramentalizar la presencia y la prestancia del futuro en ellas, pero contando siempre con que viven en la historia y pernenecen al presente, aunque se esfuercen en que no las domine el pecado, ni lo puedan, por ahora, echar fuera de sí. Así, pues, los cristianos de las comunidades confiesan, sin ningún rubor, que aguardan la redención, que no están salvados, sino en esperanza. Pero en medio de la lentación y la prueba, la debilidad y el pecado, testimonian la acción del Espíritu en ellas, él las levanta del pecado y promueve transformaciones incesantes. El testimonio consiste en que, siendo como los demás ciudadanos, el Espíritu los capacita para actuar de un modo distinto, superador.

Este testimonio es buena nueva para todos, porque el Espíritu alienta en todos y todos pueden obedecerlo. Si las comunidades no tratan de ocultar la 
distancia entre lo que son y lo que se obra en ellas, si al reconocer esa distancia, lo hacen con humildad y dan gloria a Dios, entonces se convierten en gente amable para los demás, buena nueva para todos. Sin embargo, si pretenden convertir en naturaleza, rutina, lo que es acción de Dios, acaban cayendo en hipocresía, engañándose a sí mismas y pretendiendo inútilmente engañar a los demás. La comunidad que se cree superior es, de hecho, inferior y se hace odiosa por su autoafirmación y soberbia, por su autosacralización. Entonces, creyendo que hace las veces de Dios en la historia, le quita su gloria, y se echa el desprecio sobre sí misma.

\subsection{El mayor evangelio: constituirnos en comunidad}

En estos años, estamos celebrando en Venezuela un concilio plenario. En to personal vengo insistiendo (creo que con poco éxito) en que la mayor contribución que podemos dar al país es constiluirnos en pueblo de Dios, en comunidad, de modo que la instilución eclesiástica se integre en el seno de ese pueblo de Dios y que los laicos y laicas asuman su eclesialidad, superando los primeros su papel de administradores de servicios religiosos, convirtiéndose en pacientes pastorales, y superando los segundos su papel de meros receptores; convirtiéndose unos y otros en hermanos y hermanas, al irse haciendo crislianos juntos, en un esquema de reciprocidad de dones.

Poner esto en marcha convertiría a la Iglesia en un signo para toda la sociedad. Sería un signo profético, que pone el dedo en la llaga de la exclusión y la falta de participación ciudadana y polílica, y sería también un gran paso a la transformación. Además, los cristianos que se acostumbren a vivir de una forma participativa no podrán encerrar esta actitud en la comunidad cristiana, sino que tratarán de difundirla, en el ámbito vecinal, de las relaciones laborales, de to público municipal o de lo estrictamente político.

\subsection{La comunidad sólo es cristiana cuando es germen de comunidad hu- mana}

Hemos insislido en el papel evangelizador que liene la comunidad, en base a su misma existencia espiritual, pero hay que insistir en que la condición de posibilidad es que la comunidad la ponga a producir fuera de sí misma. No es posible que una comunidad que se dice cristiana lo sea verdaderamente, si no es germen de comunidad humana. En términos evangélicos, la comunidad cristiana no existe para sí; existe como levadura en la masa. La fraternidad que no se difunde no es la fraternidad de los hijos de Dios, sino de la carne y de la sangre, así sea una comunidad de vida consagrada o una comunidad laical de élite o un consejo parroquial.

Esto es así, porque Jesús dio su Espíritu a la comunidad de discípulos para enviarlos a la misión, como el Padre lo había enviado a él (Jn 20, 21-22). La 
epifanía del Espíritu en Jesús tuvo lugar, precisamente, en el momento en que él se solidarizaba con el pueblo penitente, que acudía a bautizarse para prepararse para la venida del Señor. Cargando con el pecado del mundo cuando recibe el bautismo, se revela como el $\mathrm{Hijo}$ amado, el escogido por Dios para superar la opresión, la discriminación y el abatimiento, de modo que la fratemidad instaurada revele a Dios como el Padre de lodos. Jesús, como alianza entre Dios y la humanidad, posibilitó la superación de lo que se opone a la constitución de una humanidad fratemal. La comunidad cristiana no es la de los elegidos para salvarse de un mundo de lobos saliendo de él, sino la que en el mundo prosigue con el mismo Espíritu de Jesús el movimiento de unión fraterna que él comenzó.

Pero la comunidad no es Jesús, el salvador. Es la comunidad pecadora, que necesila ser siempre redimida, la que es enviada a superar el pecado, que deshumaniza y divide. Es la comunidad de los discípulos, quiees necesitan que se les recuerde cada día, "ojalá escuchen hoy su voz" (Sal 95, 7; Heb 3, 7-4, 13), la que es enviada a proclamar la buena nolicia. El amor de Dios permanece, en cuanto se entrega. La fe se robustece, cuando se da. La esperanza se fortifica, cuando se alienta a los abatidos. Y la Palabra se escucha con más nitidez, cuando se tiene el encargo de trasmitirla, aun captando la propia insuficiencia.

Por eso, cuando la comunidad cristiana evangeliza desde su verdad, no humilla, porque da desde abajo, como ejercicio de solidaridad humilde y gozosa, en la cual todos salen ganando. No humilla porque, al evangelizar, tiene clara su propia fragilidad y su pecado, que la asemeja a los demás, así como también la asemeja la presencia en los demás del mismo Espíritu.

\subsection{Cultivo de la democracia como cultura}

El cultivo de la democracia como cultura y la contribución al robustecimiento de la organización popular son dos concreciones de esle fomenlo de la comunitariedad humana como parte integrante del papel evangelizador de la comunidad cristiana.

Un aspeclo irrenunciable de la acción de levadura de la comunidad y de las comunidades cristianas en la comunidad urbana es el robustecimiento del tono democrático de la ciudad y de sus instituciones, esiructuras, organizaciones y asociaciones. Entendemos por ello el empleo de la palabra como puente, como modo de entender y de entenderse, de percibir las diferencias y comprenderlas como riqueza común, de negociar los conflictos de intereses, de velar porque se respete a las mayorías y porque se incluya en lo posible el sentir minoritario. Como presupuesto de este proceso tan sutil, el ideal es que las palabras entrelazadas sean vehículo de la constitución de un nosotros, en el cual no se pierda la voz de nadie, pero también en el cual cada quien ponga en común sus propios haberes para formar un verdadero cuerpo social. 
El que llamemos a Jesús Palabra de Dios, Palabra creadora, Palabra de vida, Palabra humana, que planta su tienda entre nosotros para agrupar a la humanidad dispersa por el pecado, es la fuente de la pasión por la palabra, en la comunidad cristiana. Naturalmente, ninguna palabra humana equivale a la Palabra, ni, por supuesto, las palabras de la propia comunidad. Pero el que la Palabra se haya hecho came, como puente tendido ya para siempre entre Dios y los seres humanos, y entre unos y otros seres humanos, compromete a los cristianos a utilizar las palabras no como un arma para prevalecer contra otros, sino como puente para intercomunicarse y transcender.

\subsection{Solidaridad y trascendencia}

Ahora bien, la contribución de la comunidad cristiana al entendimiento democrático exige su aporte a que la ciudad vaya transcendiéndose desde dentro. Para dar este aporte, la comunidad tiene que estar a la altura de la ciudad, es decir, liene que hacerse cargo de ella y echar la suerte con ella. Pero esta misma solidaridad le impide convertirse simplemente en una de las instituciones de la ciudad. Si se asigna el papel de representar el peso, la gloria, de la ciudad, lo que hace es sacralizarla. Y en la medida en que la sacraliza, la absolutiza. Entonces la enmascara, la deforma e impide que se transcienda a sí misma.

En la medida en que el templo es el templo de Salomón, deja de ser templo de Yahvé. En la medida en que refleja la gloria del rey, oculta la gloria de Dios. Ese no es el camino de la inculturación. " $i$ Ama la Iglesia de Francia a Francia?". Ese emplazamiento del rey cristianísimo tiene como objetivo declarado que la Iglesia no se sacralice a sí misma como inslitución, pero no para recobrar su liberlad, sino para ponerse al servicio de la nación, de la patria, del Estado; en definitiva, del rey. Es la lógica del brindis de Bolívar con los nuevos obispos, nombrados para la naciente república: "La unión del incensario con la espada de la ley es la verdadera arca de la alianza". Es la alianza entre el mandatario que porta la espada y el dignatario eclesiástico que, al incensar a Dios, le inciensa también a él.

Esa Iglesia que sacraliza pierde su sustancia propia, su transcendencia, y nada puede aportar a la ciudad. Puede sostener el orden, pero no puede contribuir a su humanización, según el paradigma de Jesús. Como supo ver muy certeramente Esquilo, en La Orestíada, Apolo puede rehabilitar a Orestes, porque no es una institución ciudadana. Apolo lo envía a Alenea, pero después de haberlo rehabilitado, cosa imposible para Atenea, que representa la sacralidad de la ciudad. Es cierto que la Iglesia no puede ser para ella misma. Es cierto que tiene que amar a Francia y que tiene que probar que la ama. Pero la Francia a la que tiene que amar no es el gobernante, el Estado, la entelequia que es la patria o la institucionalización, que configura la nación. Tiene que amar a los franceses. La lglesia no puede reconocer al Estado como el árbilro de su amor al país. La Iglesia sirve a los ciudadanos. De olra forma es sal que ha perdido el sabor. 
Pero también lo pierde, si se hace socia del Estado. La Iglesia sirve a los ciudadanos para que, desde sí mismos, se constituyan en humanos, scgún el paradigma de Jesús de Nazaret, que también la trasciende a ella. Los ciudadanos tienen que ir haciéndose humanos desde sí mismos, es decir, desde su propia cultura, que es su punto de partida y el único haber que lienen a mano. $Y$ no es que la Iglesia sacralice ese tipo humano, ese humanismo, sino que entiende la cultura en la cual ella está inserla como camino para constituirse en humanos, según Jesús de Nazaret.

Eso significa que la comunidad cristiana como tal no puede ser una institución de la ciudad, ni del Estado, ni de las fucrzas vivas, que componen el ordenamiento que llamamos la nación, o esa enlelequia que llamamos patria. La Iglesia nada sabe de eso. Y si nada sabe de eso, lampoco está en la oposición. Su ámbito de acción es la gente, los habitantes de la ciudad. Su compromiso es con el país, es decir, con sus habitantes, desde el paradigma humano que es Jesús. La Iglesia puede y debe hablar a gobiernos o a estados, desde la gente, desde cómo afecta al pueblo una medida o una polílica. No discute técnicamente las acciones gubernamentales Su perspectiva es el desarrollo humano de personas y colectividades. La medida con que juzga no puede ser tampoco ella misma como institución, sus intereses particulares. En esto consiste la libertad de la Iglesia. Una libertad no como ausencia, ni como estar por encima, ni como privilegio, sino como servicio a las personas, en orden a su transcendencia inculturada. En esto consiste el talante profćtico de la comunidad cristiana.

No se puede ocultar que, tanto los gobiemos como las masas, ticnden a anular esa distancia de modo que la Iglesia ocupe la función de sacralizar lo dado. También la institución eclesiástica se siente inclinada a aceptar el ofrecimiento. Aarón, el sacerdote, y el pueblo y sus representantes, tienden a ponerse de acuerdo y a fabricar símbolos que expresen la propia gloria, anulando la transcendencia que inquieta y perturba por su indisponibilidad. Esta propensión es especialmente constatable en el ámbito latinoamericano. La Iglesia contribuye así al reforzamiento de las identidades nacionales, regionales y locales, pero también del orden injusto. Además, su proclamación se reduce a inculcar en la gente que sean "buenos paisanos". En esle esquema se abandona la proclamación del evangelio del reino, la conversión a él, la tensión escatológica hacia él y su anticipación en el hoy de la historia. $Y$, sin embargo, csta incomodidad solidaria es la que dinamiza a las culturas y las salva desde dentro.

Por eso, la señal más inequivoca de que se quiere a la gente y no al Estado, a la patria, a la nación, a las fuerzas vivas, es cuando ese amor privilegia a los excluidos del orden vigente. La opción preferencial por los pobres es la prueba de que la Iglesia vive en tensión escalológica.

(Continuará). 